\title{
LA DEFORMACIÓN PARÓDICA DEL CATÁlOGO DE DON JUAN EN PERO... ¿HUBO aLGUNA VEZ ONCE MIL VÍRGENES? DE ENRIQUE JARDIEL PONCELA
}

\author{
Cécile FRANÇOIS \\ Université d'Orléans (France)
}

\begin{abstract}
Résumé (Fr) : Le but de cet article est de montrer comment l'écrivain espagnol Enrique Jardiel Poncela récupère l'un des invariants du mythe de Don Juan afin de le déformer par le biais de l'humour et de la parodie. L'inflation de la célèbre liste des victimes du séducteur permet à l'auteur de tourner en ridicule la version romantique du mythe qu'il place devant le miroir déformant du «star system » hollywoodien dont la vedette la plus célèbre fut sans conteste Rudolph Valentino, «l'Amant universel », qui avait pu passer au début des années vingt pour l'incarnation contemporaine, quoique un tant soit peu frelatée, du personnage légendaire. Cette hybridation démystifiante associée aux effets corrosifs de l'humour jardiélien inscrit Pero... ¿hubo alguna vez once mil vírgenes? dans l'une des tendances de l'avant-garde espagnole qui avait fait de la désacralisation des mythes et de la littérature l'un de ses objectifs prioritaires.
\end{abstract}

Mots-clés (Fr) : Jardiel Poncela ; Don Juan ; parodie ; Rudolph Valentino ; Zorrilla

Palabras claves (Es) : Jardiel Poncela; Don Juan; parodia; Rodolfo Valentino; Zorrilla

\section{Introducción}

Cuando, en el año 1930, el escritor español Enrique Jardiel Poncela emprendió la redacción de Pero... ¿hubo alguna vez once mil vírgenes?, la tercera novela de su «trilogía erótico-humorística $»^{1}$, el tema de Don Juan estaba de moda en España. En las dos décadas que precedieron a la publicación de la novela se había asistido a una intensificación de la producción -tanto teatral como ensayísticasobre el mito. Como señala Dámaso CHICHARRo CHAMORRO: «Puede afirmarse que casi no hay autor del primer tercio de nuestro siglo que no haya escrito algo sobre Don Juan, obra de creación o comentario crítico» (1991 : 39). La publicación de Pero... ¿hubo alguna vez once mil vírgenes?, subtitulada « la novela del donjuanismo moderno», se sitúa pues en esta corriente de reinterpretación y refundición del mito. En realidad, por haber sido escrita en clave de humor, igual que las dos entregas anteriores, la novela de Jardiel Poncela entronca más bien con la parodia donjuanesca muy de moda también en aquella época ${ }^{2}$. Como Valle-Inclán, Pablo Parellada o Federico Gil Asensio entre otros coetáneos suyos, el novelista madrileño pretende en su novela desmitificar a Don Juan, no solo poniendo en solfa a los personajes, situaciones y escenarios del mito, sino deformando algunos motivos como el famoso catálogo de mujeres conquistadas.

Inexistente en El Burlador de Sevilla de Tirso de Molina y en las primeras obras sobre Don Juan, el catálogo aparece por primera vez en el siglo XVII

\footnotetext{
${ }^{1}$ La trilogía consta de tres novelas redactadas entre 1928 y 1930. Se titulan respectivamente Amor se escribe sin hache (1928); ¡Espérame en Siberia, vida mía! (1929) y Pero... ¿hubo alguna vez once mil vírgenes? (1930).

${ }^{2}$ Según José Antonio Pérez Bowie, El Tenorio de Zorrilla es la obra que genera en la época mayor número de parodias como lo demuestra el elevado número de títulos que remiten a dicho texto (1992: 43).
} 
convirtiéndose a continuación en uno de los motivos más populares del mito (PEÑA, $1981: 105)^{3}$. En su Contribución al estudio del tema de Don Juan, Joaquín Casalduero señala que esta lista se encuentra ya en Cicognini y de ahí pasa a los autores franceses del siglo XVII. El crítico español añade que el siglo XIX introduce una novedad al apuntar no solo a las mujeres burladas sino también a sus respectivos maridos y amantes y resalta una variante importante en el Don Juan Tenorio de ZORRILLA : la sustitución de los maridos y amantes de las damas por los hombres muertos en desafío, muertos que no tenían que estar relacionados con las mujeres seducidas (1975: 142-143).

\section{Características del catálogo del donjuán jardielesco}

En Pero... ¿hubo alguna vez once mil vírgenes?, Jardiel Poncela descarta las innovaciones del siglo XIX para reanudar con la tradición de una lista en la que vienen anotadas exclusivamente las conquistas femeninas del seductor. Por supuesto, al pasar de un país a otro y de una obra a otra, la lista ya había sufrido algunas variaciones, creciendo o menguando al capricho de los autores, hasta vencer la marca de mil tres conquistas con el Don Giovanni de Mozart, antes de recobrar cierta normalidad con el Tenorio de Zorrilla ${ }^{4}$. El gusto de Jardiel Poncela por la deformación hiperbólica y el adínaton le lleva a seguir los pasos de Mozart y a deformar -ensanchándola hasta lo inverosímil- la famosa lista de Don Juan. En el momento en que empieza la historia, es decir en abril de 1927, el narrador nos informa de que el catálogo del seductor « señalaba la cifra monstruosa de 36.857 mujeres amadas y abandonadas » (243).

Cazador empedernido a pesar de sus reiteradas manifestaciones de hastío y cansancio, Pedro de Valdivia seducirá otras muchas mujeres en el transcurso de la novela, hasta su derrota final frente a Vivola Adamant que, según había planeado el seductor, había de ser «la mujer 36.858 » de su catálogo (191). Por tanto, durante el tiempo de la ficción (un mes exacto, desde el día 15 de abril, fecha de su primer encuentro con Vivola, hasta el día 16 de mayo, en que lleva a cabo su última conquista), Valdivia logra añadir unas 231 víctimas suplementarias a su catálogo. Asombra esta cifra cuando se la coteja con el número de hazañas eróticas del Burlador de Sevilla o del Tenorio romántico, quienes logran seducir respectivamente a cuatro mujeres para el primero y apenas dos para el segundo ${ }^{5}$ durante el transcurso de la función teatral. Más próxima a las «mille e tre » mujeres de Don Giovanni ${ }^{6}$, la lista hipertrofiada del donjuán jardielesco viene acompañada de una serie de notas, explicaciones y apuntes que llevan al seductor

\footnotetext{
${ }^{3}$ Aniano PeÑA señala que la lista se encuentra no solo en Don Juan Tenorio de Zorrilla sino «en $I l$ convitato de pietra (1650?) de Giacinto Cicognini, en Dom Juan ou le Festin de pierre (1665) de Molière, en Les Âmes du Purgatoire (1834) de Mérimée, y en Don Juan de Marana (1836) de Dumas » (1981: 105).

${ }^{4}$ El Tenorio tiene una lista de 72 conquistas.

${ }^{5}$ Aunque Don Juan Tenorio declara orgullosamente a don Luis : «Ved que las partes son dos / de la apuesta con Tenorio, / y que ganadas están », no logrará llevar a cabo la segunda conquista y se rendirá ante doña Inés (ZoRRILLA, v. 2410-2412).

${ }^{6}$ En realidad, la cifra apuntada por Leporello es de 2065 mujeres seducidas « ma in Ispagna son già mille e tre ».
} 
a organizar un verdadero archivo en el que quedan debidamente registradas y clasificadas sus conquistas.

En una nota al pie de la página 318, Luis Alemany señala que « este archivo de Pedro de Valdivia contradice una afirmación anterior de Jardiel en este mismo libro, cuando dice que Don Juan 'no es un coleccionista', porque nunca conserva las mujeres conquistadas $\gg$. Cierto es que esta aseveración de Jardiel Poncela es doblemente contradictoria puesto que, por un lado, Valdivia no abandona a las mujeres seducidas sino que selecciona a unas cuantas a las que conserva en su propia casa. Por otra parte, la elaboración de un sistema complejo y sofisticado destinado a archivar las numerosísimas conquistas que lleva a cabo a lo largo de su dilatada carrera amorosa revela su afición de coleccionista. Sin embargo, esta contradicción subrayada por Luis Alemany solo es aparente ya que Jardiel Poncela no alude aquí al personaje de Valdivia sino al mítico Don Juan. En este caso, y según su costumbre, tras realzar rotundamente una característica del mito, el escritor madrileño se dedica a demostrar cuán diferente es su protagonista para que su intención paródica no se le escape al lector.

Así, desmintiendo su propia afirmación, Jardiel PONCELA dedica un número importante de páginas a la monomanía de su donjuán, brindando al lector una descripción pormenorizada del archivo del seductor. Luis Alemany señala al respecto que se trata de un coleccionismo frío y burocrático ya que el protagonista solo conserva de sus antiguas amantes «su recuerdo impersonal y unificado » (1988 : 318). Efectivamente, el narrador apunta que «en sus armarios clasificadores, duermen reducidas a sendos cartoncitos, cuantas mujeres le entregaron sus labios, en número de $36.857 »$ (134). Ya nada recuerda la sensualidad de las amantes de Valdivia en estos «cartoncitos» fríos y rígidos. Es más, en el participio « reducidas » asoma la obsesión del seductor por dominar una realidad viva, móvil, proteica, por compendiar, resumir, abreviar, reducir en fin, la vida de estas mujeres a una serie de datos útiles y abstractos ${ }^{8}$.

«Redacta las "fichas" de las dos y mándalas mañana a Madrid para que las archiven. ¡Es magnífico! Nunca me han molestado menos dos mujeres » (381). Esta es la orden que le da Pedro de Valdivia a su criado Ramón nada más seducir (y abandonar) a Denise y a Amanda. Para él, no se trata de huir hacia nuevas aventuras olvidando rápidamente el pasado para vivir plenamente el instante como el Tenorio legendario. El seductor de Jardiel Poncela echa las cuentas de su pasado y pone fin a cada aventura dando carpetazo a sus asuntos amorosos del modo más administrativo y burocrático posible. En cierta medida, la hipertrofia del catálogo puede remitir también al afán de Valdivia de llevar a cabo una venganza a escala mundial. Este desechar y archivar sistemáticamente a las mujeres revela su deseo de adueñarse de ellas y de castigarlas metódicamente, dejando así constancia de su celo en el cumplimiento de la palabra dada a su tío Félix. En efecto, en su lecho

\footnotetext{
${ }^{7}$ La cita de Jardiel Poncela aparece en la página 97 de la novela.

${ }^{8}$ Este afán se expresa claramente en la descripción de las fichas del archivo : « [...] en cada ficha aparecía compendiada la historia de su protagonista correspondiente: nombre y apellidos, apelativo dado en las horas de intimidad, resumen de su persona y de su carácter, y procedimiento de seducción empleado » (319).
} 
mortuorio, este había pedido venganza por su muerte a manos de una mujer rencorosa :

« Júrame que vas a dedicar tu vida a enamorar mujeres y a abandonarlas cuando más enamoradas estén. [...] Jura que harás eso para vengar la ignominiosa muerte de tu tío » (234).

Esta promesa hecha al tío moribundo fue el punto de partida de la carrera erótica de Valdivia que, en adelante, había de poner todo su afán en enamorar y abandonar a cuantas mujeres le saliesen al paso. A buen seguro, su manía del recuento, plasmada en la presencia del archivo, da fe de su anhelo de agotar el vivero que representan las mujeres por seducir cumpliendo así la palabra dada. Esto explicaría que su celo administrativo rebasara los límites del archivo : « En su casa [Valdivia] ha montado una oficina con cuatro mecanógrafas y una secretaria para despachar sus asuntos amorosos », explica uno de los personajes al principio de la novela (134). Esto significa que el famoso archivo no es más que una parte de la prodigiosa máquina puesta al servicio de la actividad amatoria del donjuán de la novela. De hecho, si la función del archivo es dejar constancia del pasado, las oficinas han sido ideadas para despachar los asuntos pendientes del seductor y en particular para contestar las numerosísimas cartas que le envían sus admiradoras.

« ¿Es posible que un hombre pueda recibir ciento sesenta y seis cartas de amor todos los días? », pregunta uno de los personajes (132). Sin duda el lector de la época hubiera contestado afirmativamente. En efecto, la avalancha de cartas que le llega a diario al protagonista de la novela no deja de ser una alusión a la pletórica correspondencia que, en la realidad extradiegética, recibía el actor Rodolfo Valentino, un donjuán moderno al que se designaba como «El Amante Universal ». En un libro dedicado al «mayor seductor de la pantalla », Roger Prédal habla de unas cinco mil cartas semanales ${ }^{9}$. Es más, tras el éxito de la película The Sheik, los biógrafos del actor afirman que este recibió diez mil peticiones de mano procedentes de todos los países del mundo y de todos los estamentos de la sociedad.

Ahora bien si, como pretendía Rodolfo Valentino, cada carta que sus admiradoras le mandaban recibía una respuesta, ¿ cómo podía el actor invertir en esta actividad varias horas diarias sin perjudicar su carrera ? No cabe duda de que los productores de los estudios de Hollywood se habían planteado el problema pues desde el principio del «Star System », ellos idearon una estrategia destinada a satisfacer al público femenino a la par que les quitaba a los artistas el peso de tan fastidiosa tarea. Para contestar a las admiradoras sin por eso perder tiempo, se decidió que los empleados de los estudios les enviarían una foto con una supuesta dedicatoria de su ídolo. Acosado por centenares de mujeres enamoradas, sumergido por un alud de cartas diarias, el protagonista de Jardiel Poncela acude en parte a este sistema como da fe de ello la sarta de retratos reproducidos en la página 308 :

\footnotetext{
${ }^{9}$ Citado por Jeanne de ReCQueville (1978 : 215).
} 


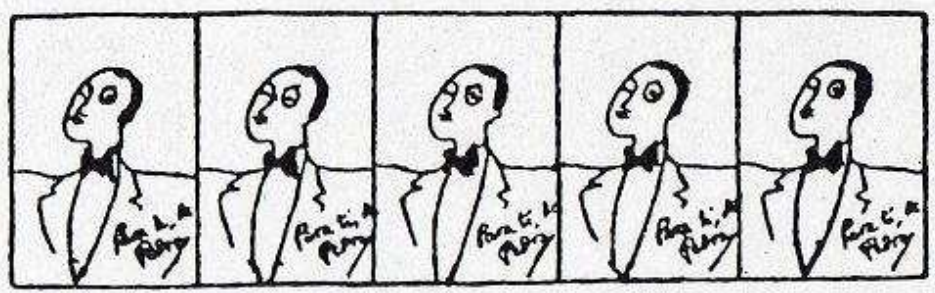

Esmoquin con solapas de raso, camisa blanca y pajarita negra, esta es precisamente la indumentaria que Rodolfo Valentino vestía durante la última gira promocional de su película El hijo del Sheik en 1926. Propulsado al rango de estrella internacional ya desde el principio de la década de los años veinte, el famoso actor tenía a su disposición dos secretarios personales cuyo único trabajo consistía en despachar la voluminosa correspondencia del actor. Cada admiradora recibía así una carta que, arriba a la derecha, ostentaba este membrete : «Oficina del señor Rodolfo Valentino» (RECQUEVILLE, 1978: 88). Con su secretaría, el protagonista de Jardiel Poncela emula a los productores de Hollywood puesto que tanto el archivo como las oficinas se señalan por su organización rigurosa y racional.

Sin embargo, a diferencia de lo que pasa en los estudios de cine, las secretarias de Valdivia no se contentan con enviar una foto sino que su trabajo consiste sobre todo en contestar cuantas cartas recibe el seductor valiéndose de unos modelos previos. «Están previstos todos los casos », declara orgullosamente Valdivia a sus visitas (316). Muy lejos estamos aquí de la visión del Tenorio redactando « cuidadoso y prolijo » el pliego destinado a doña Inés (ZORRILLA : v.34). En la época del taylorismo y de la eficacia a ultranza, el seductor ya no redacta ninguna carta y se contenta con estampar su firma al pie de cada pliego debidamente redactado por sus secretarias :

«Con este fichero -explicó Valdivia- el trabajo de contestar mi correspondencia se simplifica hasta el colmo. Yo me limito a señalar el número que corresponde de respuesta a cada carta que hay que contestar, y las mecanógrafas solo tienen que copiar el modelo correspondiente...» (317).

A buen seguro, Jardiel Poncela se divierte al aplicar al terreno de la seducción los principios de la mecanización del trabajo y amplificando de manera hiperbólica el aspecto burocrático de la actividad del donjuán en una escena colocada estratégicamente en el centro de la novela. Aquí, el escritor español lleva al extremo la ley de los estudios de Hollywood basada en la racionalización y la división del trabajo que empezaban a poner en práctica los productores, obsesionados por conseguir una rentabilidad máxima. Dentro de este sistema, la « estrella» de cine ya no era sino un instrumento más al servicio de aquella « fábrica de sueños » en que se había convertido Hollywood por aquellos años. 


\section{La influencia del catálogo en la concepción del amor del donjuán jardielesco}

La modernización de la figura legendaria de Don Juan mediante su cruce con la versión moderna del seductor hollywoodiense le permite así a Jardiel Poncela mofarse del carácter burocrático y rutinario de su protagonista, un donjuán muy alejado del modelo mítico tan brioso y arrojado. La visión que nos brinda Pero... ¿hubo alguna vez once mil vírgenes? es la de un personaje que concibe su actividad principal - el amor - como un verdadero « oficio », es más, un trabajo aburrido de «seductor de damas a domicilio » como queda estampado en su tarjeta de visita (79). Por otra parte, a propósito de la famosa lista de Don Giovanni, Jean Rousset apunta que lo que arroja el balance que presenta Leporello a Elvira no son nombres sino guarismos ( In Italia seicentoquaranta... »), que vienen completados por sendas referencias a las categorías, clases sociales, tipos físicos y edades de las víctimas. Lo que se ve en el catálogo, no son mujeres específicas sino especies, agrupaciones abstractas en las que quedan absortas o diluidas las individualidades ${ }^{10}$.

Aparentemente, el donjuán jardielesco se aleja del personaje de Mozart ya que en su fichero Valdivia conserva no solo el nombre sino los apellidos y el sobrenombre cariñoso de cada mujer. Asimismo allí quedan apuntadas algunas características de cada amante que resaltan su especificidad ${ }^{11}$. Sin embargo, como para compensar esta visión más humana y calurosa de las mujeres seducidas, Jardiel Poncela decide acentuar la manía clasificadora de Valdivia. Igual que para Don Giovanni, lo que cuenta ante todo para el donjuán jardielesco son las cifras. Por eso, al describir el archivo de Valdivia, el narrador señala « un cinturón de armarios-clasificadores en cuyos copetes los amores que allí se encerraban habían pasado a convertirse en guarismos » (318). Por supuesto la extravagante dilatación del Catálogo participa de manera activa en la degradación de la figura de Don Juan. Como apunta el narrador, para un seductor que prefiere la cantidad a la calidad, hasta « los amores [...] habían pasado a convertirse en guarismos » (318). Seductor científico, Pedro de Valdivia no deja de medir, valorar, calcular los efectos que pueda surtir la táctica escogida en su futura presa. Esta concepción de la seducción convierte al protagonista jardielesco en una verdadera máquina que traduce la vida y el amor en fórmulas matemáticas.

A lo largo de la novela, el narrador se burla de este donjuán deshumanizado y de su prodigiosa memoria gracias a la cual Valdivia es capaz de asociar instantáneamente los nombres de sus amantes con los números de su archivo. Pero si, paralelamente al Catálogo, su memoria se ha ensanchado desmedidamente, también se ha vuelto más selectiva concentrándose exclusivamente en los datos

\footnotetext{
${ }^{10}$ « Ce qui ressort du fastueux bilan présenté par Leporello à Elvire, ce ne sont pas des noms, ce sont des nombres, "In Italia seicentoquaranta...", et des catégories, classes sociales, types physiques, âges ; nous devons comprendre : non pas telle ou telle, le nom est oublié par celui qui, un jour, le prononça, mais des espèces, des groupements abstraits dans lesquels sont absorbées et annulées les personnes singulières » (RousseT, $1978: 45$ ).

${ }_{11}$ «En cada ficha, Pedro de Valdivia hace constar el nombre y apellidos de la dama, el apelativo que la dio en las horas de intimidad, un breve resumen de su historia, una reseña de su persona, otra de su temperamento y carácter y, al final, el procedimiento de que se valió para seducirla » (134).
} 
relativos a las amantes. En cuanto al resto de su vida, Valdivia parece totalmente incapaz de recordar las cosas más elementales. Ni se acuerda de los acontecimientos o de los personajes históricos más conocidos que forman parte del acervo cultural español. Esta característica del protagonista proporciona uno de los momentos más graciosos de la novela. Así, al oír a su criado hablar de Madrid, ciudad de la que es oriundo Valdivia, este pregunta de manera ingenua : « ¿La capital de España, verdad? ». Los fallos de su memoria se hacen aún más patentes cuando Ramón le contesta afirmativamente, añadiendo que Madrid es capital de España desde la época de Felipe II. Al oír esta respuesta, «Valdivia se quedó pensativo, murmurando: - Felipe II... Felipe II.... ¿Dónde he oído yo ese nombre antes de ahora?... » (272).

Si la pasión por los guarismos no resulta extraña en un « hombre para quien el amor ha sido siempre una fórmula matemática » (409), el narrador enfatiza los efectos cómicos de dicha pasión poniendo en escena al general Schneider, un personaje que se entretiene haciendo cálculos estrafalarios acerca de las hazañas del seductor. Las cifras se disparan entonces y con los récords establecidos bien se podría llenar otro archivo tan dilatado como el de Valdivia. Así, al principio de la novela, al oír que el seductor «en su casa tiene cartas de amor en cantidad suficiente para abarrotar un vapor correo » (131), el general empieza a calcular el número de cartas recibidas por Valdivia al día, al mes y al año sucesivamente :

« ¿Es posible que un hombre pueda recibir ciento sesenta y seis cartas de amor todos los días? Tenga usted en cuenta que al mes resultan cuatro mil novecientas ochenta, y al año sesenta mil quinientas noventa, y al...» (132)

No cabe duda de que el general se disponía a pregonar el número de cartas recibidas por Valdivia en un siglo antes de ser interrumpido por uno de los personajes presentes. De hecho, asombra la rapidez y la facilidad con las que el general maneja las cifras como si de una máquina de calcular se tratase. Pero el virtuosismo del personaje, lejos de suscitar la admiración de su entorno, lo deja o bien indiferente o irritado y el lector por su parte se ríe de la energía gastada por el general en una actividad tan improcedente. La comicidad estriba aquí no solo en este desajuste sino sobre todo en el proceso de cosificación de los personajes que el narrador irá intensificando a lo largo de la novela. De hecho, paulatinamente, la afición de Valdivia a los guarismos se va convirtiendo en verdadera compulsión. En efecto, lo que llama la atención en el donjuán jardielesco es la reacción instantánea y automática que tiene al divisar a su futura presa. Este rasgo característico del protagonista es lo que le sirve al narrador para desarrollar el proceso desmitificador del personaje legendario.

Jardiel Poncela acude aquí a la teoría del filósofo francés, Henri Bergson, uno de los primeros en haber analizado los mecanismos de la risa la cual nace, según él, de un efecto de rigidez mecánica. En Pero... ¿hubo alguna vez once mil vírgenes?, como un muñeco que salta de repente de su caja, Valdivia reacciona siempre de la misma manera cuando se encuentra en presencia de una mujer. Esta «deformación profesional» se hace patente en la escena del tren que le lleva a Niza. Al encontrar a la joven Amanda, « la voz interior que avisaba las aventuras a Valdivia le dictó una cifra: - La 37.082... » (377). Asimismo, la belleza de Denise 
no suscitó ninguna emoción particular en el seductor. Es más, cuando la vio por primera vez, solo «apretó contra su pecho el brazo de la dama y pensó, apuntándosela ya en su haber: - ¡La 37.081! » (365) ${ }^{12}$.

En cuanto a las mujeres ya seducidas, Valdivia parece incapaz de oír el nombre de una de ellas sin sacar a colación el número bajo el cual ella figura en su catálogo. Al joven admirador que le pregunta : «Pero, ¿no es Florencia amante de usted? », Valdivia contesta en el acto : «Sí. De las recientes: la 36.843 »(336). Lo mismo pasa con Corina Rey, muchacha sensible, perdidamente enamorada del donjuán, la cual conmueve al joven admirador con sus lágrimas y suspiros. Cuando este le pide aclaraciones a Valdivia, el seductor se contenta con facilitarle una explicación rápida y vaga para añadir en seguida : "Corina es el número 16.351 de mi Catálogo... Un "caso" interesante, no crea... » (300). Ahora bien, si las réplicas y reacciones del personaje ya logran resaltar su monomanía, Jardiel Poncela acentúa el efecto cómico de las mismas anunciando gráficamente ciertas escenas de seducción con subtítulos en forma de recuadros que pueden leerse como una serie de hitos en el camino triunfal del donjuán :

$$
\text { LA 37.081. DENISE } \text { o } \text { LA 37.082. AMANDA }^{13}
$$

Se echa de ver que, si a lo largo del relato cada una de las etiquetas lleva un número seguido del nombre de la mujer seducida, la carrera de Valdivia concluye de manera apoteósica con un recuadro más grande que solo registra una sucesión de guarismos :

\begin{tabular}{|l|}
\hline LAS $37.083,37.084,37.085$ \\
$37.086,37.087$ y $37.088 \ldots$
\end{tabular}

El efecto acumulativo acelera el ritmo de la acción que culmina con la visión de un donjuán presa de verdadero frenesí. El lector tiene la impresión de que Valdivia ha sido cogido en una especie de engranaje y ya nada podrá detenerlo en su loca carrera en pos de las mujeres. Esta aceleración final pondrá de relieve la suspensión brutal y definitiva de la actividad del seductor en el capítulo siguiente, a raíz de su fracaso con la «doñajuana » de la novela. Si, en la vida del donjuán jardielesco, todo se calcula, no es extraño que la carrera de Valdivia no acabe a los pies de una doña Inés sino en casa de un médico que saca un balance cuantitativo de su actividad amatoria. Con este recuento final, el donjuán de Pero...¿hubo alguna vez once mil vírgenes? pierde su aura mágica y queda definitivamente desmitificado :

\footnotetext{
12 Jean RoussET señala que las únicas mujeres dotadas de una realidad singular son aquellas que pertenecen al presente del seductor y de su público. Se trata del grupo restringido de las heroínas que son nombradas y conquistadas ante nuestros ojos antes de caer, ellas también, en el olvido, sepultadas en el Catálogo (1978 : 46). Para el protagonista de Jardiel, estas mujeres conquistadas ante los ojos del lector son guarismos antes de ser individuos. Solo son presas que el seductor quiere añadir a su lista de trofeos.

${ }^{13}$ Pero... ¿hubo alguna vez once mil vírgenes?, p. 368 y 375.

${ }^{14}$ Pero... ¿hubo alguna vez once mil vírgenes?, p. 392.
} 
« [...] De modo que usted ha dado en su vida tres millones setecientos ocho mil ochocientos besos... Vamos a suponer que en cada beso usted no ha absorbido más que un miligramo de rouge... Bien. Pues ¿sabe usted la cantidad de rouge que almacena su estómago? ¡Cerca de cuatro kilos, señor Valdivia! » (502)

\section{El « broche de oro » del catálogo}

En opinión de don Luis Mejía, el rival de Don Juan, la lista para ser completa debe ostentar el nombre de « una novicia / que esté para profesar » (ZORRILLA : v. 669-670). En seguida Don Juan Tenorio recoge el guante declarando orgullosamente que «a la novicia unir[á] / la dama de algún amigo / que para casarse esté », lo cual significa una doble transgresión de las leyes, humanas y divinas (ZORRILLA : v.673-675). Como no podía faltar, Jardiel Poncela recupera la aventura del burlador y de la novicia que, según Chicharro, Chamorro es puro tópico desde el siglo XVII $(1991,230)$. En la novela, es el joven admirador de Valdivia quien hace de don Luis al preguntar al seductor : « ¿Y monja? ¿No tiene usted ninguna monja?»(325). En seguida, Jardiel Poncela desactiva la carga subversiva de la apuesta romántica gracias al símil que completa la frase : «como si se hallase ante el mostrador de una tienda ». El personaje de don Luis pierde su poder tentador y corruptor al asumir aquí el papel de un cliente que pide informaciones sobre alguna mercancía. Valdivia, por su parte, hace las veces de dependiente amable y solícito al contestar : « ¿Cómo no? Ya lo creo... Tengo dos novicias y una madre superiora » (325). La intención paródica de Jardiel Poncela se hace patente en la difracción del personaje de la novicia. Fiel a su costumbre de deformar, ampliándolos, los elementos constitutivos del mito, el autor duplica esta figura a la que añade, por si fuera poco, la de una Superiora de convento. El archivo de Valdivia ostenta por lo tanto un triple trofeo religioso : Sor Reverberación de las Catorce Llagas, Sor Insolación de los Diez Puñales y la Superiora que, a diferencia de las novicias, no lleva nombre.

Huelga decir que Jardiel Poncela se divierte mucho al inventar para sus dos personajes nombres tan estrafalarios que contrastan rotundamente con la sobriedad del de Inés, la heroína de Zorrilla. Lo que en seguida llama la atención es el parecido de los nombres, siendo el segundo como un eco del primero. Ambos tienen, en efecto, la misma estructura : están compuestos de dos sustantivos que encierran sendos semas de luz y terminan con el mismo sufijo («Reverberación » / «Insolación»). Estos nombres van acompañados de un complemento formado de un numeral («catorce » / «diez ») al que le sigue un sustantivo que pertenece al campo léxico de la agresión y del dolor («llagas» / «puñales»). Con la elección de los sustantivos «Reverberación» e «Insolación», Jardiel Poncela enfatiza de manera graciosa el aura que suele emanar de los santos, esa luz sobrenatural que la imaginería popular representa bajo la forma de una aureola. Simultáneamente se efectúa un desplazamiento del plano espiritual al plano material, por la elección de dos términos que evocan respectivamente un fenómeno científico (la reverberación) y sus consecuencias físicas o médicas (la insolación). Ahora bien como señala Bergson, 
« On obtiendra un effet amusant quand on développera un symbole ou un emblème dans le sens de leur matérialité et qu'on affectera de conserver à ce développement la même valeur symbolique que l'emblème » $(1901: 89)^{15}$.

Aunque el complemento del nombre («de las Catorce llagas » / «e los Diez Puñales ») connota el sufrimiento, la presencia del numeral añade un toque burlesco al conjunto por ser una deformación de la imagen de las « cinco llagas de Cristo ». Con el parecido de los dos nombres, Jardiel Poncela pone de manifiesto la semejanza entre las dos novicias que pueden aparecer ora como gemelas o clones, ora como una doble representación burlesca de doña Inés. La disposición en la página de las fichas de las dos novicias refuerza esta impresión. Estas llevan respectivamente los números 9.906 y 9.907 y están colocadas, una al lado de la otra (326) :

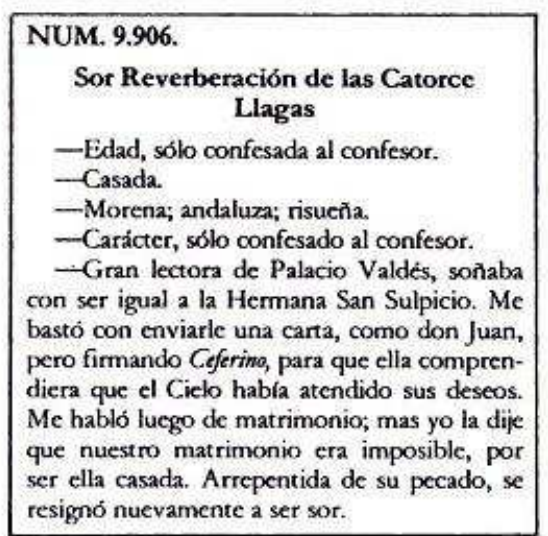

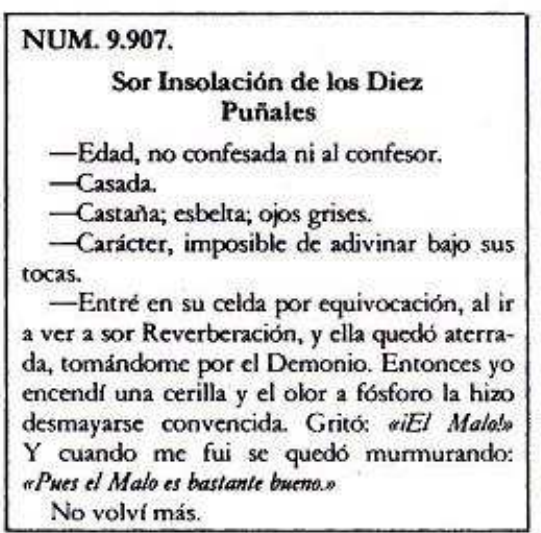

Se nota que las fichas constan de los mismos apartados redactados de manera casi idéntica. A veces solo se diferencian por unos detalles como es el caso para la edad de las dos novicias. En la primera ficha viene apuntada la frase siguiente : «Edad, sólo confesada al confesor». El mismo juego de palabras se encuentra en la segunda ficha con una leve modificación que acentúa la frivolidad y la coquetería de las monjitas : «Edad, no confesada ni al confesor». El segundo apartado remite al estado civil de las novicias. Como el lector asocia automáticamente el noviciado con la castidad y el celibato, se espera naturalmente que las fichas ostenten la mención «solteras ». Pero Jardiel Poncela juega con el concepto religioso según el cual las monjas son las esposas de Cristo para alejar todavía más a sus dos novicias de la figura de la casta doña Inés. Por otra parte, la mención «casadas » le permite reducir a uno los dos envites de la apuesta del Tenorio (una novicia que esté para profesar y una dama que esté para casarse). Paradójicamente, la profanación del sacramento del matrimonio (agravado, aquí, por la esencia divina del esposo) pierde su carácter escandaloso por el tratamiento liviano del tema y la frivolidad de las dos «víctimas » del donjuán. El retrato de las « gemelas » culmina con la escena del equívoco de Valdivia. Tal es el parecido

\footnotetext{
${ }^{15}$ « Se obtendrán efectos cómicos siempre que se desarrolle un símbolo o un emblema en un sentido material y se afecte conservar a esta prolongación igual valor simbólico que al emblema mismo ».
} 
entre las dos monjitas que Valdivia seduce a Sor Insolación «por equivocación, al ir a ver a Sor Reverberación » (326).

$\mathrm{Si}$ el retrato humorístico de las novicias permite a Jardiel Poncela deslucir la figura radiante de la doña Inés romántica, accesoriamente sirve para burlarse de otras creaciones literarias, entre las cuales figura la Hermana San Sulpicio. En la época en que el autor redactaba su novela, este famoso personaje literario volvía a gozar del favor del público gracias a una adaptación cinematográfica ${ }^{16}$. En Pero... ¿hubo alguna vez once mil vírgenes?, Valdivia asocia abiertamente Sor Reverberación a la amable heroína de Armando Palacio Valdés :

«Gran lectora de Palacio Valdés, soñaba con ser igual a la Hermana San Sulpicio. Me bastó con enviarle una carta, como don Juan, pero firmada Ceferino, para que ella comprendiera que el Cielo había atendido sus deseos » (326). ${ }^{17}$

Por su parte, Sor Insolación no deja de recordar a María Rosario, la heroína de la Sonata de primavera de Valle-Inclán como se puede apreciar en el relato que nos brinda Valdivia :

«Entré en su celda [...] y ella quedó aterrada, tomándome por el Demonio. Entonces yo encendí una cerilla y el olor a fósforo la hizo desmayarse convencida. Gritó: “iEl Malo!” ” (326).

Esta reacción horrorizada de la novicia es un eco del grito de espanto de María Rosario - « ¡Fue Satanás!... ¡Fue Satanás!... » - que concluye la novela de ValleInclán (1904 : 96). Sin embargo, el remate de la aventura de Valdivia y Sor Insolación no puede ser más distinto al de la Sonata de primavera. Jardiel Poncela le quita, en efecto, todo carácter trágico a la escena y borra la profanación y el sacrilegio que representaba el acto del seductor, concluyendo con la declaración satisfecha y maliciosa de Sor Insolación: «Pues el Malo es bastante bueno » (326).

La parodia de los grandes clásicos de la literatura española prosigue con el relato de la seducción de la madre superiora. Ahora el blanco de la pullas del narrador es Fray Luis de León y su famoso poema «Vida retirada » ${ }^{18}$ que se convierte en la novela en una «Oda a la vagancia». Valdivia explica aquí que conquistó a la Superiora « recitándole trozos escogidos de Fray Luis de León », y añade que « el trozo que más le gustaba de Fray Luis era la oda a la vagancia »:

\footnotetext{
${ }^{16}$ La Hermana San Sulpicio, inspirada en la novela de Armando Palacio Valdés, fue una de las películas más taquilleras de la época. Rodada en 1927 por Florián Rey, un director muy apreciado por el público, contaba con la participación de la nueva actriz en boga, Imperio Argentina, en el papel estelar.

${ }_{17}^{17}$ Notemos que la yuxtaposición de los nombres de Don Juan y Ceferino hacen de la novicia un gracioso compendio de dos heroínas literarias: doña Inés y la Hermana San Sulpicio.

${ }_{18}$ " ¿Qué descansada vida / la del que huye el mundanal ruido, / y sigue la escondida / senda por donde han ido / los pocos sabios que en el mundo han sido!». Así empieza el poema cuyo famosísimo primer verso permite un equívoco que el lector capta en seguida.
} 
«- ¿La oda a la vagancia?

- Sí. Esa tan popular que empieza diciendo:

¿Qué descansada vida,

la que huye del mundanal ruido... » (326)

A lo largo de la escena de la conquista de la madre superiora, Valdivia hace alarde de virtuosismo en el arte de la fantasía verbal sacando provecho de la polisemia del participio «descansado » que interpreta en su sentido más literal. Pero, además de la dilogía, el seductor se vale también de una antanaclasis para sacar los efectos humorísticos deseados. En la réplica del seductor aparece así alternativamente la palabra «trozo » en dos sentidos distintos (fragmento de una obra literaria / parte de un cuerpo) cuando comenta sus relaciones con la madre superiora: « [La deslumbré] recitándole trozos escogidos de Fray Luis de León.[...] En cuanto al trozo que más le gustaba de mí, nunca pude saberlo » (326). Por fin, el remate humorístico de la aventura se consigue gracias a la repetición de la palabra «superior», primero como sustantivo, luego como adjetivo. Al joven admirador que le pregunta intrigado : «Y realmente, ¿era superiora?», Valdivia contesta : « ¡Era superiorísima! » con un tono picaresco que no deja al lector ninguna duda sobre lo escabroso de la aventura (326). En realidad, el acierto del remate procede también de la creación del barbarismo « superiorísima» que añade un superlativo a un comparativo en una especie de encarecimiento que resalta paradójicamente las disposiciones eróticas de un personaje ligado por el voto de castidad.

\section{Conclusión}

Caricaturas de la doña Inés romántica, las novicias y la madre superiora no solo introducen una nota burlesca en las aventuras del donjuán jardielesco sino que participan activamente en la desacralización del drama religioso-fantástico de Zorrilla. Alzándose en contra del Romanticismo al que define como un «estado poético comatoso merced al cual la razón se disuelve en suspiros » (362), Jardiel Poncela nos presenta su propia versión del Tenorio poniendo en escena a un seductor frío, calculador y rutinario que se sitúa al extremo opuesto del Don Juan mítico. Por otra parte, la ostentación de un Catálogo amplificado hasta lo absurdo y la instalación de unas verdaderas oficinas destinadas a prolongar su actividad amatoria nos informan sobre la concepción del amor del donjuán jardielesco. Ajeno a los impulsos de la sangre y del corazón, el protagonista de Pero... ¿hubo alguna vez once mil vírgenes? no ve en las mujeres seducidas más que unos trofeos de caza que se amontonan en sus oficinas bajo la forma de unos cartoncitos irrisorios.

Con la última novela de su «trilogía erótico-humorística », Enrique Jardiel Poncela nos ofrece una graciosa variación sobre el mito de Don Juan cuyas características procura deconstruir sistemáticamente, como es el caso aquí con el famoso Catálogo. La deformación hiperbólica de la lista de mujeres le permite al humorista madrileño convertir a Don Juan en un seductor burocrático más interesado por la ordenación de su fichero que por el placer de la conquista. Además, el cotejo de la organización de las oficinas del protagonista jardielesco 
con la del trabajo en los estudios de cine de Hollywood permite que se solapen las figuras de Don Juan y de Rodolfo Valentino, encarnando este una versión moderna pero harto adulterada del mito. Al arremeter así con las armas del humor y de la parodia contra la visión romántica del mito, Enrique Jardiel Poncela se inscribe dentro de la corriente de la vanguardia artística, uno de cuyos proyectos consistía en « la superación de vestigios románticos, como el sentimentalismo o el patetismo, mediante el poder disolvente y corrosivo de un nuevo concepto del humor » (REY BRIONES, $1992:$ 233).

Con Pero... ¿hubo alguna vez once mil vírgenes?, Enrique Jardiel Poncela alcanza la meta que se había propuesto, la de ofrecer a su lector una «sátira literaria » que lograse dinamitar el mito y hacer reír al público a expensas de Don Juan. Lo curioso sin embargo es la rara obsesión del escritor por el personaje legendario pues, aunque en la década siguiente abandonará la narrativa para dedicarse casi exclusivamente al teatro, no por eso dejará de tratar el tema de Don Juan. Ya en 1932 escribirá Usted tiene ojos de mujer fatal, la versión teatral de la novela, una comedia amable y optimista que termina de modo convencional con el consabido final feliz. Dos años más tarde estrenará Angelina o el honor de un brigadier antes de escribir Las cinco advertencias de Satanás, que constituirá la cuarta y última variación del autor sobre el tema de Don Juan. No cabe duda de que el interés que sigue manifestando Jardiel Poncela por el mito - al menos hasta 1935 - revela una extraña fascinación a la que parece no poder sustraerse. Por cierto, $i$ no resulta a la vez paradójica y divertida esta atracción por el mítico Don Juan en un autor que ha ido afirmando y demostrando a lo largo de Pero... ¿hubo alguna vez once mil vírgenes? que « Don Juan es un idiota »?

\section{BIBLIOGRAFÍA}

Alemany, Luis (1988), edición de Pero... ¿hubo alguna vez once mil vírgenes? de Enrique Jardiel Poncela, Madrid, Cátedra.

BERGSON, Henri (1900), Le Rire, Paris, P.U.F.

CASAlduero, Joaquín (1975), Contribución al estudio del tema de Don Juan en el teatro español, Madrid, ed. José Porrúa Turanzas, S.A.

Chicharro Chamorro, Dámaso (1991), Introducción a Juan de Mañara, de Manuel y Antonio Machado, Madrid, Espasa Calpe, col. « Austral » A 236.

CRIADO, Isabel, « De El movimiento V.P. a Pero.....hubo alguna vez once mil vírgenes? », Ínsula ${ }^{\circ} 529$, enero de 1991, pp.7-8.

Feal Deibe, Carlos (1984), En nombre de Don Juan. Estructura de un mito literario. Amsterdam-Philadelphia, John Benjamins Publishing Company.

JaRdiel PONCELA, Enrique (1988), Pero... ¿hubo alguna vez once mil vírgenes?, edición de Luis Alemany, Madrid, Cátedra.

PeÑA, Aniano (1981), edición de Don Juan Tenorio de José Zorrilla, Madrid, Cátedra.

PÉREZ BOWIE, José Antonio (1992), « Mecanismos de titulación en el teatro de humor de la preguerra (aproximación semiótica) », en El teatro en España entre la tradición y la vanguardia (1918-1939), Madrid, S.C.I.C., p.31-43. 
ReCQueVILLE, Jeanne de (1978), Rudolph Valentino, Paris, Editions FranceEmpire.

REY BRIONES, Antonio del (1992), La novela de Ramón Gómez de la Serna, Madrid, Editorial Verbum.

RousSeT, Jean (1978), Le Mythe de Don Juan, Paris, Armand Colin.

SERRANO, Carlos (1996). Carnaval en noviembre. Parodias Teatrales Españolas de Don Juan Tenorio. Recopilación, edición e introducción, Alicante, Diputación Provincial de Alicante, Instituto de Cultura Juan Gil-Albert, « Literatura y crítica / $16 »$.

VALle-InClán, Ramón del (1993), Sonata de primavera, Madrid, Espasa Calpe, Col. « Austral » $\mathrm{n}^{\circ} \mathrm{A} 37$.

Zorrilla, José (1981), Don Juan Tenorio, edición de Aniano Peña, Madrid, Cátedra. 